Published in final edited form as:

Heart Fail Clin. 2010 April ; 6(2): 187-200. doi:10.1016/j.hfc.2009.11.001.

\title{
Atrial Fibrillation in Congestive Heart Failure
}

\author{
Steven A. Lubitz, M.D. ${ }^{\text {a,b }}$, Emelia J. Benjamin, M.D, Sc.M. ${ }^{C}$, and Patrick T. Ellinor, M.D., \\ Ph.D.d \\ a Research fellow, Cardiovascular Research Center, Massachusetts General Hospital, Boston, MA \\ b Research fellow, Center for Cardiovascular Disease Prevention, Brigham and Women's Hospital, \\ Boston, MA \\ c Professor, Section of Cardiology, Preventive Medicine, and Whitaker Cardiovascular Institute, \\ Boston University School of Medicine; Department of Epidemiology, Boston University School of \\ Public Health, Boston, MA; National Heart, Lung, and Blood Institute's Framingham Heart Study, \\ Framingham, MA
}

d Assistant Professor, Cardiac Arrhythmia Service \& Cardiovascular Research Center, Massachusetts General Hospital, Boston, MA

\section{Synopsis}

Atrial fibrillation and congestive heart failure are morbid conditions that share common risk factors and frequently coexist. Each condition predisposes to the other, and the concomitant presence of the two identifies individuals at increased risk for mortality. Recent data have emerged which help elucidate the complex genetic and non-genetic pathophysiological mechanisms that contribute to the development of atrial fibrillation in individuals with congestive heart failure. Clinical trial results offer insights into the noninvasive prevention and management of these conditions, though the emergence of newer technologies, such as catheter ablation for atrial fibrillation, have yet to be studied extensively in patients with congestive heart failure.

\section{Keywords}

Atrial fibrillation; congestive heart failure; genetic mutations; etiology; pathophysiology; management

\section{Introduction}

Atrial fibrillation (AF) and congestive heart failure (CHF) are among the most common medical conditions and are associated with significant morbidity. These two conditions share similar risk factors, frequently coexist, and have additive adverse effects when occurring in conjunction. Much evidence has amassed regarding the nature of the relations between $\mathrm{AF}$ and CHF. In this review we will discuss AF in the context of CHF, with a particular emphasis on the underlying pathophysiological mechanisms and genetic basis of AF. We will also address

Corresponding author: Patrick T. Ellinor, M.D., Ph.D. Cardiac Arrhythmia Service and Cardiovascular Research Center, Massachusetts General Hospital, 149 13th Street, Charlestown, MA 02129, Phone: 617-724-8729, Fax: 617-726-5806, pellinor@ partners.org.

Co-author contact information: Steven A. Lubitz, M.D. Division of Preventive Medicine, Brigham and Women's Hospital, 900 Commonwealth Avenue, Boston, MA 02215, Phone: 917-701-3321, Fax: 270-717-8428, slubitz@ partners.org

Emelia J. Benjamin, M.D., Sc.M. Professor of Medicine and Epidemiology, Boston University Schools of Medicine and Public Health;, The Framingham Heart Study, 73 Mount Wayte Ave. Suite 2, Framingham, MA 01702-5827, Phone: 617-638-8968, Fax: 617-638-8969, emelia@bu.edu

Financial disclosure: Drs. Lubitz and Benjamin report no financial conflicts of interest. Dr. Ellinor is a consultant to Sanofi-Aventis. 
the proper management of $\mathrm{AF}$ when it occurs in conjunction with $\mathrm{CHF}$, on the basis of recent clinical trials and practice guidelines.

\section{Epidemiology}

AF is the most common arrhythmia seen in clinical practice, and is responsible for significant morbidity (1). Over 2.3 million individuals in the United States currently have AF (2), and as many as 5.6 to 12.1 million individuals are projected to be affected by $2050(2,3)$. The lifetime risk of developing AF after the age of 40 is $26 \%$ for men, and $23 \%$ for women (4). The presence of AF confers a five-fold increased risk of stroke (5), a significantly increased risk of dementia (6), and an almost two-fold increased risk of death (5). Moreover, the incidence of AF is rising (7), and thus presents a significant healthcare burden as it accounts for an increasing proportion of hospitalizations (8). Health care costs are approximately five times greater for individuals with AF than for those without AF (9).

CHF has a similar prevalence affecting over 5 million individuals in the United States (10). After the age of 40, the lifetime risk of developing CHF is over 20\% (11). CHF portends a grave prognosis, with over half of individuals dying within five years of diagnosis (12), though some estimates indicate that survival may be improving $(12,13)$. CHF accounts for a significant proportion of the healthcare budget, with an estimated cost of $\$ 34.8$ billion in 2008 (10).

\section{Prevalence of comorbid AF and CHF}

As both AF and CHF occur frequently, the simultaneous presence of these two conditions is common. The prevalence of AF in patients with systolic left ventricular dysfunction and CHF ranges from $6 \%$ for asymptomatic patients or for those with minimal symptoms (14), to between $15 \%$ and $35 \%$ for patients with New York Heart Association (NYHA) class II-IV symptoms (15-23). In two large epidemiologic studies $(24,25)$, the prevalence of AF was greater in CHF patients with preserved ejection fractions than in those with left ventricular systolic dysfunction, though the rates of AF were similar in patients with systolic as compared to diastolic CHF in one clinical trial (20).

The concomitant presence of both AF and CHF in many patients may be explained by shared underlying risk factors and mechanisms, or a causal relation between the entities. Indeed, many risk factors for AF have been recognized as leading risk factors for CHF (Table). The shared risk factors include hypertension, diabetes mellitus, ischemic heart disease, and valvular heart disease (26). Additionally, evidence of myocarditis, one potential cause of dilated cardiomyopathy and CHF, has also been implicated in the genesis of $\operatorname{AF}(27,28)$. In one series, $\mathrm{AF}$ was directly attributable to CHF in $5 \%$ of cases (29).

\section{Temporal relations of AF and CHF}

The temporal relations of AF and CHF were examined in a study of 1470 patients with new onset AF or CHF from the Framingham Heart Study (30). The average follow-up was 5.6 years after the development of AF, and 4.2 years after the development of CHF. Among patients who developed $\mathrm{AF}, 26 \%$ had a prior or concurrent diagnosis of $\mathrm{CHF}$, and $16 \%$ of the remaining patients subsequently developed CHF during the follow-up period. Among patients who developed CHF, 24\% had a prior or concurrent diagnosis of AF, and 17\% developed AF during the subsequent follow-up period. For patients diagnosed with AF, the incidence of developing CHF was 33 per 1000 person-years. Conversely, among individuals diagnosed with CHF, the incidence of developing AF was 54 per 1000 person-years.

The association between AF and the development of CHF was also analyzed in a study of 3288 patients diagnosed with $\mathrm{AF}$ at the Mayo Clinic (7). Twenty-four percent developed CHF during a mean follow-up of 6.1 years, with an incidence of 44 per 1000 patient-years. A spike in the 
incidence of CHF was seen early after the diagnosis of AF, with $7.8 \%$ of cases occurring within the first 12 months, and approximately 3\% per year thereafter. Patients with lone AF fared well, as only about $2 \%$ developed CHF within 5 years of being diagnosed with AF (7).

\section{Prognosis of comorbid AF and CHF}

Whereas substantial morbidity and mortality is attributable to each of these individual conditions, the concomitant presence of $\mathrm{AF}$ and $\mathrm{CHF}$ identifies individuals with a higher risk for death than with either condition alone. The prognostic impact of incident AF or CHF among individuals diagnosed with the other comorbid condition was assessed by investigators from the Framingham Heart Study (30). The development of AF in individuals with CHF was associated with a hazard ratio for death of 1.6 in men, and 2.7 in women, during follow-up of 4.2 years. Similarly, the development of $\mathrm{CHF}$ among individuals with $\mathrm{AF}$ was associated with a hazard ratio for death of 2.7 in men, and 3.1 in women, over a follow-up of 5.6 years.

The clinical consequences of AF are derived from the loss of organized atrial activity and absence of coordinated atrial mechanical function. Impaired contraction of the atria may cause blood stasis and the potential for thrombus formation, particularly in the left atrial appendage, with a resultant risk of stroke. This risk of stroke is increased in patients with CHF (31). Hundreds of electrical impulses arrive at the atrioventricular node and are variably transmitted, resulting in fast or slow heart rates and irregular ventricular depolarization. Patients may experience symptoms such as palpitations, dyspnea, or fatigue. The electrical and mechanical features of AF may also have hemodynamic consequences. A reduction in cardiac output is attributable to both the irregularity of ventricular contractions and the loss of atrial mechanical activity, which impairs ventricular filling $(32,33)$. In fact, restoration of sinus rhythm results in a roughly $30 \%$ increase in cardiac output (34), though the significance of atrial contribution to cardiac output has been controversial in patients with preexisting elevations in left atrial pressure $(35,36)$. Persistent tachycardia due to poor rate control has also been reported to result in a cardiomyopathy (37).

Thus, AF and CHF commonly coexist, share a similar risk factor profile, and have adverse hemodynamic effects. The simultaneous presence of both diseases identifies individuals at substantially increased risk of cardiovascular events and death.

\section{Pathophysiology of AF in CHF}

The pathophysiologic basis of AF is complex and incompletely understood (38). Initial mechanistic explanations for AF cited reentry as a principal factor (39-42). The multiple wavelet hypothesis, proposed by Moe and Abildskov,(41) stated that the development of AF depended on the perpetuation of a sufficient number of "randomly wandering wavelets" created as a normal occurrence due to heterogeneous repolarization. The hypothesis maintained that adequate atrial mass, short refractory periods, and conduction velocities slow enough to permit temporal disparities in depolarization and repolarization in the atria favored the development of these reentrant wavelets.

This argument is predicated on the concept that the wavelength of an electrical signal also represents the minimal pathway length that must be present to sustain a reentrant circuit. If a pathway is shorter, then a reentrant electrical stimulus will encounter refractory tissue upon completing the circuit and terminate. In contrast, if the pathway is longer then the electrical signal may encounter excitable tissue upon completing the circuit, thereby perpetuating the previous cycle. The wavelength, and thus the pathway length, is proportional to both the refractory period of the tissue, as well as the conduction velocity. This model explains precipitants of AF that shorten the atrial effective refractory period or decrease conduction velocity. 
The focal automaticity theory was an early competing hypothesis that explicitly challenged the role of reentrant rhythms in the genesis of AF, instead proposing that repetitively firing foci serve as the driving factor (43). In fact, a contemporary paradigm acknowledges complexity in the development of AF, recognizing the role of both susceptible atrial substrate, which may foster reentry, as well focal electrophysiologic triggers (Figure 1) (44).

\section{Susceptible atrial substrate}

Fibrosis-Atrial fibrosis is commonly observed in patients with AF, both with and without underlying organic heart disease, and is considered a major factor contributing to the development and maintenance of $\operatorname{AF}(27,28,45)$. Fibrosis results from increased interstitial collagen deposition, which may disrupt cell-to-cell coupling and thereby alter signal conduction. Indeed, areas with decreased conduction velocities and heterogeneous conduction have been observed in animal models of $\mathrm{AF}$ and fibrosis $(46,47)$.

Fibrosis accompanies aging and is observed both with ischemia and myocyte stretch $(48,49)$. Activation of the renin-angiotensin-aldosterone system provokes myocardial fibrosis, which appears to be mediated through upregulation of the TGF- $\beta 1$ pathway (50). Indirect evidence of the contributory role of atrial fibrosis provoked by the renin-angiotensin-aldosterone neurohormonal axis is derived from clinical trials that have documented a significant reduction in the risk of new-onset or recurrent AF with angiotensin converting enzyme inhibitors or angiotensin receptor blockers $(51,52)$.

Myocyte stretch-Myocyte stretch is another important factor contributing to AF susceptibility. Indeed, several pathological conditions associated with increased left atrial pressure are closely linked to the development of AF, including hypertension, mitral valve disease, and CHF. Myocyte stretch stimulates collagen deposition by fibroblasts, in part mediated via angiotensin II and TGF- $\beta 1$ pathways (48). Additionally, stretch causes acute alterations in electrophysiological properties that are favorable to the development and maintenance of $\mathrm{AF}$ via mechanoelectric feedback mechanisms (53).

\section{Electromechanical remodeling}

Experimental models in goats demonstrate that prior AF promotes an environment favorable to subsequent episodes of AF through both electrophysiological (54) as well as structural remodeling (55). Intracellular calcium overload causing a reduction of L-type calcium currents may contribute to atrial remodeling (56). Additional mechanisms of atrial remodeling may include intracellular glycogen accumulation accompanied by sarcomere loss (55), and diminished myocyte energy reserves (53). Accompanying proarrhythmic electrophysiological changes have been observed, such as decreases in myocyte resting potential, shortening of the atrial effective refractory period, and characteristic alterations in the morphology of the action potential $(54,56)$. Grossly, structural changes resulting from AF may manifest as left atrial enlargement (57), which predisposes to recurrent AF.

Elements promoting susceptible atrial substrate are often interrelated, underscoring the difficulty of identifying discrete mechanisms that result in AF. For example, both myocyte stretch and prior AF have been linked to atrial fibrosis (48).

\section{Focal triggers}

In addition to the role of susceptible atrial substrate, recent evidence has emerged which supports a critical role for focal triggers in the development of AF in many patients with this arrhythmia. These focal triggers most commonly arise from within the pulmonary veins ( 58 , 59 ), and conduct to the left atrium through sleeves of muscular tissue in the pulmonary veins (60). The importance of these triggers has been underscored by the success of pulmonary vein 
isolation in preventing recurrences of AF in many patients $(61,62)$. The mechanisms resulting in these triggers remain unclear, though automaticity, triggered activity, and microreentry have all been implicated (63). The observation that myocyte stretch increases pulmonary vein foci firing once again illustrates the interdependence of mechanisms contributing to AF (64). Ectopic foci have also been identified in other areas of the heart such as the posterior left atrium, coronary sinus, superior vena cava, and ligament of Marshall (65). Additionally, atrioventricular nodal reentrant tachycardias (66), as well as atrioventricular bypass tracts may also trigger $\mathrm{AF}(67)$.

\section{Modulating factors}

In addition to susceptible atrial substrate and electrophysiologic triggers, modulating factors such as autonomic tone have been identified in the development of $\operatorname{AF}(68,69)$. Vagal denervation has been explored for the prevention of recurrent $\mathrm{AF}$ with promising initial results (69). Inflammation may also be associated with the development of AF in patients with concomitant cardiovascular disease (70). In fact, treatment with corticosteroids in addition to beta blockade during the postoperative period reduced the risk of developing postoperative $\mathrm{AF}$ by roughly $50 \%$ among patients undergoing cardiac surgery without any preexisting history of $\mathrm{AF}(71)$.

\section{Role of Genetics}

An abundance of epidemiological data implicates a heritable contribution to the development of AF. In a prospective cohort study encompassing patients from the Original and Offspring cohorts from the Framingham Heart Study, the odds ratio of developing AF over 4 years among participants with a parental history of AF was 1.85 , and increased to 3.23 when limiting the analysis to parents and offspring who developed AF under the age of 75 (72). Other studies have confirmed that up to approximately one-third of individuals with AF have a positive family history of the condition (73-76). In a study encompassing over 5000 patients diagnosed with $\mathrm{AF}$ in Iceland, the relative risk of developing AF was 1.77 among members with an affected first-degree relative, and declined with each successive degree of relation (77).

Analyses of patients with familial AF have exposed mutations in genes encoding potassium (78-84) and sodium $(75,76,85-87)$ channels (Figure 2), as well as atrial natriuretic peptide (88), and have identified several loci associated with AF (89-92). Mutations in ion channels may contribute to AF by their effect on the atrial action potential, which is comprised of multiple tightly coordinated electrical currents. The majority of identified potassium channel mutations result in a gain of channel function. Such an increase in an outward potassium current would produce more rapid repolarization of atrial myocytes, shorten the atrial effective refractory period, and thus predispose to reentry $(78-81,83,84,93)$. Interestingly, a loss-offunction mutation in the ultrarapid delayed rectifier potassium current $\left(I_{\text {Kur }}\right)$ has been identified which prolongs the action potential and facilitates early after depolarizations, particularly under adrenergic stimulation (82). As discussed below, prolongation of the action potential has been observed in patients with CHF, suggesting that triggered activity may play an important role in initiating AF in this setting (94). Some loss-of-function mutations in sodium channels decrease ionic current, prolong the atrial action potential duration, and may predispose to $\mathrm{AF}$ in a similar manner.(95)(85). More recently, somatic mutations in gap junction proteins have been identified in patients with idiopathic AF (95), but the prevalence of such mutations is unknown. Despite mechanistic insights gleaned from identification of these mutations, ion channel mutations are rare causes of $\mathrm{AF}(96)$.

In some cases, identification of genes implicated in cardiomyopathies has shed light on possible shared biological mechanisms between CHF and AF. In some patients with a familial cardiomyopathy and AF, mutations have been identified in SCN5A, or the cardiac sodium 
channel gene also associated with the Brugada and long QT syndromes $(97,98)$. Similarly, mutations in the laminin $\mathrm{A} / \mathrm{C}$ gene, a nuclear envelope protein, have been identified in patients with familial dilated cardiomyopathy that is preceded by the development of $\operatorname{AF}(99,100)$. The mechanisms by which such mutations cause arrhythmias and a cardiomyopathy remain unclear.

Most mutations identified thus far have been discovered by linkage or candidate gene analysis. More recently, genome-wide association studies have been employed to search for genetic variation that may underlie common diseases such as $\operatorname{AF}(101,102)$. Genome-wide association studies can identify genetic variants associated with a particular phenotype by scanning for hundreds of thousands of single nucleotide polymorphisms in patients both with and without the condition of interest. The identified variants may have a direct pathogenic role in the development of the condition; however, in most cases, such variants are simply serving as a marker of a genetic region associated with a risk of the condition. Genome-wide association studies represent a major advance owing to the fact that they provide rapid assessment of thousands of markers throughout the genome and are not constrained by existing understanding of physiology.

A recent genome-wide association study in Iceland has identified two variants on chromosome $4 q 25$ associated with AF (101). Replication in three additional cohorts of European ancestry reproduced the associations, while replication in a cohort of Chinese descent confirmed the association with one of the variants (101). No known gene is present in the genomic block containing the two variants, though two potential candidate genes, PITX2 and ENPEP, are located in close proximity. PITX2 plays an important role in cardiac development by directing asymmetric morphogenesis of the heart (103). Knockout of PITX2 in a mouse model suppresses the default pathway for sinoatrial node formation in the left atrium $(104,105)$. ENPEP encodes an aminopeptidase responsible for breakdown of angiotensin II in the vascular endothelium. Knockout of ENPEP in a mouse model resulted in systemic HTN but no arrhythmias (106). Investigation of the causal mechanisms by which these variants are related to AF is ongoing. In two subsequent genome-wide association studies, a second common AF susceptibility locus was identified on chromosome 16q22 within the ZFHX3 gene. $(107,108)$

\section{Specific implications in CHF}

Thus it is clear that electrical triggers, susceptible substrate, and modulating factors are important for the promotion of AF. Genetic factors may promote AF by increasing susceptibility to reentry, triggered activity, disrupting cell-to-cell communication, and through other currently as yet undefined mechanisms. Several of the discussed pathophysiological mechanisms are of particular importance in patients with CHF (Figure 1).

Increased atrial refractoriness has been observed in CHF patients that develop AF, suggesting that the origins of the arrhythmia in this patient population may differ from those classically described (94). A variety of ion channel current abnormalities have been reported in experimental CHF models, including a reduction in L-type $\mathrm{Ca}^{2+}$ current $\left(I_{\mathrm{Ca}}\right)$, transient outward $\mathrm{K}+$ current $\left(I_{\mathrm{to}}\right)$, and slow delayed rectifier current $\left(I_{\mathrm{Ks}}\right)(109)$. Notably, CHF is accompanied by an increase in the $\mathrm{Na}^{+} / \mathrm{Ca}^{2+}$ transmembrane exchange channel current, which exchanges three monovalent sodium ions for every one divalent calcium ion. This net positive intracellular imbalance can predispose to delayed after depolarizations, resulting in arrhythmias initiated by triggered activity. Indeed, data from a pacing-induced animal model of CHF demonstrate that abnormalities in calcium handling prolong the atrial action potential and foster $\mathrm{AF}$ through triggered activity (110). Adrenergic stimulation occurs in CHF, and is a well-known cause of triggered activity. The role of adrenergic stimulation in the genesis of AF is not clear (111). In parallel to ion channel remodeling present in patients with CHF, heterogeneous distribution of connexins, which form gap junctions, has been observed in both animal models of atrial hemodynamic overload as well as in humans with a history of CHF (112). 
Elevations in left atrial and pulmonary venous pressure present in CHF promote AF as well. Myocyte stretch increases firing from ectopic foci such as the pulmonary veins through mechanoelectrical feedback (64). Additionally, increased fibrosis results from myocyte stretch. Gross evidence of structural remodeling includes left atrial enlargement, which predisposes to $\mathrm{AF}(113,114)$. Although increased atrial refractoriness has been observed clinically in patients with CHF, shortening of the atrial refractory period has been reported in experimental models of left atrial stretch, suggesting that many competing processes may be occurring simultaneously in these patients (115).

Neurohormonal activation is another principal feature of CHF that also promotes AF. Upregulation of both the renin-angiotensin-aldosterone and adrenergic systems causes myocardial fibrosis, which impairs impulse propagation $(46,116)$. Fibrosis is thought to play a prominent role in the development of AF in patients with CHF. In an experimental pacing model of CHF, fibrosis, rather than ion channel remodeling, produced lasting effects that correlated with the maintenance of induced AF (117). Nonetheless, angiotensin II may have independent effects on ion currents which promote AF (118).

\section{Treatment}

\section{Thromboembolism prophylaxis}

Thromboembolism prophylaxis, ventricular rate control, and restoration of sinus rhythm when indicated, are the goals of AF therapy (1). The risk of cerebral thromboembolism in patients with AF is increased in those with CHF (31). Annual stroke risk can be estimated using validated scoring schemes $(31,119)$, and guidelines provide a recommended approach to the prevention of thromboembolism in patients based on their underlying risk. Generally, warfarin is advisable for the prevention of ischemic cerebrovascular events in patients with CHF and an additional stroke risk factor (1).

\section{Rate and rhythm control}

Recent controlled trials of patients with predominantly persistent and asymptomatic AF demonstrated no advantage of a rhythm control strategy comprised of antiarrhythmic drug therapy and electrical cardioversion over a rate control strategy in terms of survival or morbidity (120-124). A meta-analysis of these trials demonstrated a reduction in the combined endpoint of all-cause death or thromboembolic stroke with a rate control strategy (125).

However, rhythm control strategies in these trials were only moderately successful, with the maintenance of sinus rhythm ranging from $23 \%$ to $64 \%$ over variable periods of follow-up. Post-hoc analyses of these and other trials demonstrate that achievement of sinus rhythm is associated with improved survival (126) and quality of life $(127,128)$. The observation that non-cardiovascular deaths were greater in the rhythm control arm than in the rate control arm of the AFFIRM trial has provoked speculation that the benefits of maintaining sinus rhythm were offset by the harmful effects of antiarrhythmic drug therapy (129).

These trials were not adequately powered to assess the optimal management strategy of AF in patients with CHF. More recently, the results of the Atrial Fibrillation and Congestive Heart Failure Trial (AF-CHF) were reported (130). This randomized controlled trial assessed cardiovascular mortality among patients with concomitant AF and CHF treated with either a rate or rhythm control strategy. Over 1300 patients were enrolled, with a mean left ventricular ejection fraction of $27 \%$. One third of patients had NYHA class III or IV symptoms, and over two-thirds had persistent AF. Over $80 \%$ of patients randomized to the rhythm control arm were treated with amiodarone, and $40 \%$ underwent electrical cardioversion. During a mean followup period of 37 months, sinus rhythm was documented in $75-80 \%$ of patients in the rhythm control arm by 12-lead electrocardiogram at each follow-up visit, whereas sinus rhythm was 
present in 30-40\% of patients in the rate control arm at each visit. No difference was observed in cardiovascular mortality between strategies during the follow-up period. These data suggest that a rhythm control strategy consisting of pharmacologic and electrical cardioversion for stable patients with concomitant $\mathrm{AF}$ and $\mathrm{CHF}$ does not improve cardiovascular survival. These results may not pertain to patients that are hemodynamically unstable as a result of AF. Additionally, the impact of other rhythm or rate control strategies, such as catheter ablation for AF, or atrioventricular node ablation with pacing, was not assessed adequately in this or other trials comparing rate and rhythm control strategies. In a smaller trial of 61 patients randomized to rhythm control with amiodarone and direct cardioversion or rate control and followed for one year, an improvement in left ventricular function and some quality of life parameters was observed among those in the rhythm control arm.(131)

\section{Catheter ablation}

Catheter ablation for AF, specifically pulmonary vein isolation, has become an increasingly popular therapy for the treatment of AF. Recent controlled trials suggest that in carefully selected patients, catheter ablation is superior to a medical rhythm control strategy for the prevention of recurrent disease during short-term follow-up, with success rates ranging from 56-87\% (132). Yet subjects in these trials predominantly were healthy, had paroxysmal rather than persistent or permanent $\mathrm{AF}$, and were typically without structural heart disease.

Catheter ablation for AF was assessed in 58 patients with CHF in one non-randomized controlled trial (133). Sinus rhythm was present in $78 \%$ of patients following ablation after approximately one year, although repeat ablations were required in half of the patients. Improvements in functional status, symptoms, and ejection fraction were noted with ablation.

Similarly, in a prospective cohort study, sinus rhythm was achieved in $73 \%$ of patients with left ventricular systolic dysfunction who underwent pulmonary vein isolation at approximately 14 months of follow-up, as compared to $87 \%$ of patients with preserved left ventricular function (134). Sixty-eight percent of the patients with left ventricular systolic dysfunction had NYHA class III symptoms.

Despite promising initial results, there are presently no data that demonstrate that catheter ablation improves survival in patients with CHF. Moreover, results from studies of catheter ablation for AF must be interpreted in the context of the study designs, which often were not randomized, involved few patients, and provided only short-term follow-up.

\section{Atrioventricular nodal ablation and pacemaker placement}

Ablation of the atrioventricular node with implantation of a single right ventricular lead for permanent pacing, also referred to as the "ablate and pace" approach, is effective for the achievement of rate control in patients with $\mathrm{AF}$ and rapid ventricular response, and results in greater symptom control than pharmacologic therapy aimed at controlling the ventricular rate in patients with left ventricular systolic dysfunction and CHF (135). Yet right ventricular pacing can be associated with progressive left ventricular dysfunction, whereas biventricular pacing results in reduced morbidity and mortality in systolic CHF patients with NYHA class III or IV symptoms in sinus rhythm and with a prolonged QRS (136). In a prospective cohort study of patients with conventional indications for biventricular pacemaker implantation, the benefits of biventricular pacing in a subgroup of patients with $\mathrm{AF}$ were maximized when biventricular pacing was induced nearly $100 \%$ of the time by atrioventricular node ablation (137).

Improvements in the ejection fraction and functional capacity were seen when compared to patients who received biventricular pacing less than $85 \%$ of the time. Other data demonstrate improvements in a variety of functional and symptomatic parameters in patients with $\mathrm{AF}$ and systolic CHF with a wide QRS who are treated with biventricular pacemakers (138). The 
Atrioventricular Junction Ablation Followed by Resynchronization Therapy in Patients with $\mathrm{CHF}$ and AF trial (139) trial will compare pharmacologic rate control therapy to atrioventricular node ablation with biventricular pacemaker implantation in patients with symptomatic permanent $\mathrm{AF}$ and $\mathrm{CHF}$, irrespective of underlying QRS duration.

While the ablate and pace approach achieves rate control, it does not restore sinus rhythm and necessitates permanent implantation of a mechanical pacemaker. AV nodal ablation with biventricular pacing was compared to AF ablation in a pilot study of 35 subjects with CHF and systolic left ventricular dysfunction (140). In the Pulmonary Vein Isolation Versus AV Nodal Ablation With Biventricular Pacing for Patients With Atrial Fibrillation With Congestive Heart Failure (PABA CHF) study, pulmonary vein isolation was associated with greater improvement in symptoms and ejection fraction as compared with the ablate and biventricular pacing group.

Definitive trials assessing the effectiveness of AF ablation as compared with an ablate and ventricular pacing strategy are warranted. In the meantime, atrioventricular node ablation and ventricular pacing remains a reasonable option for the management of patients in whom the achievement of adequate rate control with pharmacologic therapy is inadequate (1).

\section{Renin-angiotensin-aldosterone axis inhibitors and beta-blockers}

Importantly, pharmacological agents commonly used in the management of patients with systolic CHF both prevent incident AF and reduce recurrences in patients with concomitant $\mathrm{AF}$ and $\mathrm{CHF}$, again reinforcing the shared mechanisms of these diseases. Both angiotensin converting enzyme inhibitors and angiotensin receptor blockers are effective in preventing the onset of AF. In one meta-analysis of randomized trials assessing the use of an angiotensin converting enzyme inhibitor or angiotensin receptor blocker, the relative risk of developing $\mathrm{AF}$ among patients treated with either medication was reduced by $28 \%$ (51). Patients with CHF enjoyed a relative risk reduction of $44 \%$, with a greater benefit seen among those with more severe left ventricular systolic dysfunction. In another meta-analysis, the overall risk reduction for the development of new onset AF among patients treated with an angiotensin converting enzyme inhibitor or angiotensin receptor blocker was $18 \%$, and patients with a history of CHF had a particular benefit with a risk reduction of $43 \%$ (52).

Further, a systematic review of randomized placebo-controlled trials in patients with CHF demonstrated that the addition of beta-blockers in addition to ACE-I therapy was associated with a relative risk reduction of $27 \%$ in the incidence of AF over an average follow-up of 1.35 years (141). However, no preventative effect of beta-blockade was observed in the SENIORS trial, which studied the use of nebivolol in elderly patients ( $\geq 70$ years old) with either diastolic or systolic CHF.

\section{Conclusion}

$\mathrm{AF}$ and CHF share many risk factors, frequently coexist, and identify individuals at high risk of cardiovascular morbidity. The pathophysiological mechanisms of AF in patients with CHF are complex and potentially involve elements of reentry, triggered activity and enhanced automaticity. Therefore, it is unlikely that a treatment strategy aimed at any one of these mechanisms alone will restore sinus rhythm. A rhythm control strategy consisting of antiarrhythmic drugs and electrical cardioversion in stable patients with AF and CHF adds no benefit to a rate control strategy. Newer therapies aimed at restoring sinus rhythm, such as catheter ablation for $\mathrm{AF}$, and rate control therapies such as atrioventricular nodal ablation with biventricular pacing, have emerged as potential alternatives to conventional rhythm and rate control strategies. Future trials will be necessary to delineate the role for such techniques in the multitude of patients with these morbid conditions. 


\section{Acknowledgments}

Dr. Lubitz is supported by an NIH training grant (5T32HL007575). Dr. Ellinor receives support from the Disque Deane Foundation.

\section{References}

1. Fuster V, Ryden LE, Cannom DS, et al. ACC/AHA/ESC 2006 Guidelines for the Management of Patients with Atrial Fibrillation: a report of the American College of Cardiology/American Heart Association Task Force on Practice Guidelines and the European Society of Cardiology Committee for Practice Guidelines (Writing Committee to Revise the 2001 Guidelines for the Management of Patients With Atrial Fibrillation): developed in collaboration with the European Heart Rhythm Association and the Heart Rhythm Society. Circulation 2006;114:e257-354. [PubMed: 16908781]

2. Go AS, Hylek EM, Phillips KA, et al. Prevalence of diagnosed atrial fibrillation in adults: national implications for rhythm management and stroke prevention: the AnTicoagulation and Risk Factors in Atrial Fibrillation (ATRIA) Study. JAMA 2001;285:2370-5. [PubMed: 11343485]

3. Miyasaka Y, Barnes ME, Gersh BJ, et al. Secular trends in incidence of atrial fibrillation in Olmsted County, Minnesota, 1980 to 2000, and implications on the projections for future prevalence. Circulation 2006;114:119-25. [PubMed: 16818816]

4. Lloyd-Jones DM, Wang TJ, Leip EP, et al. Lifetime risk for development of atrial fibrillation: the Framingham Heart Study. Circulation 2004;110:1042-6. [PubMed: 15313941]

5. Kannel WB, Wolf PA, Benjamin EJ, Levy D. Prevalence, incidence, prognosis, and predisposing conditions for atrial fibrillation: population-based estimates. Am J Cardiol 1998;82:2N-9N.

6. Ott A, Breteler MM, de Bruyne MC, van Harskamp F, Grobbee DE, Hofman A. Atrial fibrillation and dementia in a population-based study. The Rotterdam Study Stroke 1997;28:316-21.

7. Miyasaka Y, Barnes ME, Gersh BJ, et al. Incidence and mortality risk of congestive heart failure in atrial fibrillation patients: a community-based study over two decades. Eur Heart J 2006;27:936-41. [PubMed: 16399778]

8. Wattigney WA, Mensah GA, Croft JB. Increasing trends in hospitalization for atrial fibrillation in the United States, 1985 through 1999: implications for primary prevention. Circulation 2003;108:711-6. [PubMed: 12885749]

9. Wu EQ, Birnbaum HG, Mareva M, et al. Economic burden and co-morbidities of atrial fibrillation in a privately insured population. Curr Med Res Opin 2005;21:1693-9. [PubMed: 16238910]

10. American Heart Association. Heart disease and stroke statistics--2008 update. Dallas, Texas: American Heart Association; 2008.

11. Lloyd-Jones DM, Larson MG, Leip EP, et al. Lifetime risk for developing congestive heart failure: the Framingham Heart Study. Circulation 2002;106:3068-72. [PubMed: 12473553]

12. Levy D, Kenchaiah S, Larson MG, et al. Long-term trends in the incidence of and survival with heart failure. N Engl J Med 2002;347:1397-402. [PubMed: 12409541]

13. Roger VL, Weston SA, Redfield MM, et al. Trends in heart failure incidence and survival in a community-based population. JAMA 2004;292:344-50. [PubMed: 15265849]

14. Dries DL, Exner DV, Gersh BJ, Domanski MJ, Waclawiw MA, Stevenson LW. Atrial fibrillation is associated with an increased risk for mortality and heart failure progression in patients with asymptomatic and symptomatic left ventricular systolic dysfunction: a retrospective analysis of the SOLVD trials. Studies of Left Ventricular Dysfunction. J Am Coll Cardiol 1998;32:695-703. [PubMed: 9741514]

15. van Veldhuisen DJ, Aass H, El Allaf D, et al. Presence and development of atrial fibrillation in chronic heart failure. Experiences from the MERIT-HF Study. Eur J Heart Fail 2006;8:539-46. [PubMed: 16567126]

16. De Ferrari GM, Klersy C, Ferrero P, et al. Atrial fibrillation in heart failure patients: prevalence in daily practice and effect on the severity of symptoms. Data from the ALPHA study registry. Eur J Heart Fail 2007;9:502-9. [PubMed: 17174599] 
17. Flather MD, Shibata MC, Coats AJ, et al. Randomized trial to determine the effect of nebivolol on mortality and cardiovascular hospital admission in elderly patients with heart failure (SENIORS). Eur Heart J 2005;26:215-25. [PubMed: 15642700]

18. Poole-Wilson PA, Swedberg K, Cleland JG, et al. Comparison of carvedilol and metoprolol on clinical outcomes in patients with chronic heart failure in the Carvedilol Or Metoprolol European Trial (COMET): randomised controlled trial. Lancet 2003;362:7-13. [PubMed: 12853193]

19. Corell P, Gustafsson F, Schou M, Markenvard J, Nielsen T, Hildebrandt P. Prevalence and prognostic significance of atrial fibrillation in outpatients with heart failure due to left ventricular systolic dysfunction. Eur J Heart Fail 2007;9:258-65. [PubMed: 17027330]

20. Olsson LG, Swedberg K, Ducharme A, et al. Atrial fibrillation and risk of clinical events in chronic heart failure with and without left ventricular systolic dysfunction: results from the Candesartan in Heart failure-Assessment of Reduction in Mortality and morbidity (CHARM) program. J Am Coll Cardiol 2006;47:1997-2004. [PubMed: 16697316]

21. Deedwania PC, Singh BN, Ellenbogen K, Fisher S, Fletcher R, Singh SN. Spontaneous conversion and maintenance of sinus rhythm by amiodarone in patients with heart failure and atrial fibrillation: observations from the veterans affairs congestive heart failure survival trial of antiarrhythmic therapy (CHF-STAT). The Department of Veterans Affairs CHF-STAT Investigators. Circulation 1998;98:2574-9. [PubMed: 9843465]

22. Maggioni AP, Latini R, Carson PE, et al. Valsartan reduces the incidence of atrial fibrillation in patients with heart failure: results from the Valsartan Heart Failure Trial (Val-HeFT). Am Heart J 2005;149:548-57. [PubMed: 15864246]

23. Swedberg K, Olsson LG, Charlesworth A, et al. Prognostic relevance of atrial fibrillation in patients with chronic heart failure on long-term treatment with beta-blockers: results from COMET. Eur Heart J 2005;26:1303-8. [PubMed: 15767288]

24. Bhatia RS, Tu JV, Lee DS, et al. Outcome of heart failure with preserved ejection fraction in a population-based study. N Engl J Med 2006;355:260-9. [PubMed: 16855266]

25. Owan TE, Hodge DO, Herges RM, Jacobsen SJ, Roger VL, Redfield MM. Trends in prevalence and outcome of heart failure with preserved ejection fraction. N Engl J Med 2006;355:251-9. [PubMed: 16855265]

26. Ho KK, Pinsky JL, Kannel WB, Levy D. The epidemiology of heart failure: the Framingham Study. J Am Coll Cardiol 1993;22:6A-13A. [PubMed: 8509564]

27. Frustaci A, Caldarulo M, Buffon A, Bellocci F, Fenici R, Melina D. Cardiac biopsy in patients with "primary" atrial fibrillation. Histologic evidence of occult myocardial diseases. Chest 1991;100:3036. [PubMed: 1864099]

28. Frustaci A, Chimenti C, Bellocci F, Morgante E, Russo MA, Maseri A. Histological substrate of atrial biopsies in patients with lone atrial fibrillation. Circulation 1997;96:1180-4. [PubMed: 9286947]

29. Cowie MR, Wood DA, Coats AJ, et al. Incidence and aetiology of heart failure; a population-based study. Eur Heart J 1999;20:421-8. [PubMed: 10213345]

30. Wang TJ, Larson MG, Levy D, et al. Temporal relations of atrial fibrillation and congestive heart failure and their joint influence on mortality: the Framingham Heart Study. Circulation 2003;107:2920-5. [PubMed: 12771006]

31. Gage BF, Waterman AD, Shannon W, Boechler M, Rich MW, Radford MJ. Validation of clinical classification schemes for predicting stroke: results from the National Registry of Atrial Fibrillation. JAMA 2001;285:2864-70. [PubMed: 11401607]

32. Naito M, David D, Michelson EL, Schaffenburg M, Dreifus LS. The hemodynamic consequences of cardiac arrhythmias: evaluation of the relative roles of abnormal atrioventricular sequencing, irregularity of ventricular rhythm and atrial fibrillation in a canine model. Am Heart J 1983;106:28491. [PubMed: 6869209]

33. Clark DM, Plumb VJ, Epstein AE, Kay GN. Hemodynamic effects of an irregular sequence of ventricular cycle lengths during atrial fibrillation. J Am Coll Cardiol 1997;30:1039-45. [PubMed: 9316536]

34. Scott ME, Patterson GC. Cardiac output after direct current conversion of atrial fibrillation. Br Heart J 1969;31:87-90. [PubMed: 5764969] 
35. Greenberg B, Chatterjee K, Parmley WW, Werner JA, Holly AN. The influence of left ventricular filling pressure on atrial contribution to cardiac output. Am Heart J 1979;98:742-51. [PubMed: 495426]

36. Mukharji J, Rehr RB, Hastillo A, et al. Comparison of atrial contribution to cardiac hemodynamics in patients with normal and severely compromised cardiac function. Clin Cardiol 1990;13:639-43. [PubMed: 2208823]

37. Packer DL, Bardy GH, Worley SJ, et al. Tachycardia-induced cardiomyopathy: a reversible form of left ventricular dysfunction. Am J Cardiol 1986;57:563-70. [PubMed: 3953440]

38. Nattel S. New ideas about atrial fibrillation 50 years on. Nature 2002;415:219-26. [PubMed: 11805846]

39. Mines GR. On dynamic equilibrium in the heart. J Physiol 1913;46:349-83. [PubMed: 16993210]

40. Garrey WE. The nature of fibrillary contraction of the heart; its relation to tissue mass and form. Am J Physiol 1914;33:397-414.

41. Moe GK, Abildskov JA. Atrial fibrillation as a self-sustaining arrhythmia independent of focal discharge. Am Heart J 1959;58:59-70. [PubMed: 13661062]

42. Lewis T. Observations upon flutter and fibrillation. Part IX. The nature of auricular fibrillation as it occurs in patients. Heart 1921;8:193-227.

43. Scherf D, Terranova R. Mechanism of auricular flutter and fibrillation. Am J Physiol 1949;159:13742. [PubMed: 15391089]

44. Natale A, Raviele A, Arentz T, et al. Venice Chart international consensus document on atrial fibrillation ablation. J Cardiovasc Electrophysiol 2007;18:560-80. [PubMed: 17456138]

45. Kostin S, Klein G, Szalay Z, Hein S, Bauer EP, Schaper J. Structural correlate of atrial fibrillation in human patients. Cardiovasc Res 2002;54:361-79. [PubMed: 12062341]

46. Li D, Fareh S, Leung TK, Nattel S. Promotion of atrial fibrillation by heart failure in dogs: atrial remodeling of a different sort. Circulation 1999;100:87-95. [PubMed: 10393686]

47. Verheule S, Sato T, Everett Tt, et al. Increased vulnerability to atrial fibrillation in transgenic mice with selective atrial fibrosis caused by overexpression of TGF-beta1. Circ Res 2004;94:1458-65. [PubMed: 15117823]

48. Burstein B, Nattel S. Atrial fibrosis: mechanisms and clinical relevance in atrial fibrillation. J Am Coll Cardiol 2008;51:802-9. [PubMed: 18294563]

49. Everett, THt; Olgin, JE. Atrial fibrosis and the mechanisms of atrial fibrillation. Heart Rhythm 2007;4:S24-7. [PubMed: 17336879]

50. Chen K, Mehta JL, Li D, Joseph L, Joseph J. Transforming growth factor beta receptor endoglin is expressed in cardiac fibroblasts and modulates profibrogenic actions of angiotensin II. Circ Res 2004;95:1167-73. [PubMed: 15539634]

51. Healey JS, Baranchuk A, Crystal E, et al. Prevention of atrial fibrillation with angiotensin-converting enzyme inhibitors and angiotensin receptor blockers: a meta-analysis. J Am Coll Cardiol 2005;45:1832-9. [PubMed: 15936615]

52. Anand K, Mooss AN, Hee TT, Mohiuddin SM. Meta-analysis: inhibition of renin-angiotensin system prevents new-onset atrial fibrillation. Am Heart J 2006;152:217-22. [PubMed: 16875900]

53. Allessie MA, Boyden PA, Camm AJ, et al. Pathophysiology and prevention of atrial fibrillation. Circulation 2001;103:769-77. [PubMed: 11156892]

54. Wijffels MC, Kirchhof CJ, Dorland R, Allessie MA. Atrial fibrillation begets atrial fibrillation. A study in awake chronically instrumented goats. Circulation 1995;92:1954-68. [PubMed: 7671380]

55. Ausma J, Wijffels M, Thone F, Wouters L, Allessie M, Borgers M. Structural changes of atrial myocardium due to sustained atrial fibrillation in the goat. Circulation 1997;96:3157-63. [PubMed: 9386188]

56. Van Wagoner DR, Pond AL, Lamorgese M, Rossie SS, McCarthy PM, Nerbonne JM. Atrial L-type Ca2+ currents and human atrial fibrillation. Circ Res 1999;85:428-36. [PubMed: 10473672]

57. Petersen P, Kastrup J, Brinch K, Godtfredsen J, Boysen G. Relation between left atrial dimension and duration of atrial fibrillation. Am J Cardiol 1987;60:382-4. [PubMed: 2956853]

58. Haissaguerre M, Jais P, Shah DC, et al. Spontaneous initiation of atrial fibrillation by ectopic beats originating in the pulmonary veins. N Engl J Med 1998;339:659-66. [PubMed: 9725923] 
59. Chen SA, Hsieh MH, Tai CT, et al. Initiation of atrial fibrillation by ectopic beats originating from the pulmonary veins: electrophysiological characteristics, pharmacological responses, and effects of radiofrequency ablation. Circulation 1999;100:1879-86. [PubMed: 10545432]

60. Nathan H, Eliakim M. The junction between the left atrium and the pulmonary veins. An anatomic study of human hearts. Circulation 1966;34:412-22. [PubMed: 5922708]

61. Oral H, Pappone C, Chugh A, et al. Circumferential pulmonary-vein ablation for chronic atrial fibrillation. N Engl J Med 2006;354:934-41. [PubMed: 16510747]

62. Wazni OM, Marrouche NF, Martin DO, et al. Radiofrequency ablation vs antiarrhythmic drugs as first-line treatment of symptomatic atrial fibrillation: a randomized trial. Jama 2005;293:2634-40. [PubMed: 15928285]

63. Nattel S. Basic electrophysiology of the pulmonary veins and their role in atrial fibrillation: precipitators, perpetuators, and perplexers. J Cardiovasc Electrophysiol 2003;14:1372-5. [PubMed: 14678116]

64. Chang SL, Chen YC, Chen YJ, et al. Mechanoelectrical feedback regulates the arrhythmogenic activity of pulmonary veins. Heart 2007;93:82-8. [PubMed: 16905626]

65. Lin WS, Tai CT, Hsieh MH, et al. Catheter ablation of paroxysmal atrial fibrillation initiated by nonpulmonary vein ectopy. Circulation 2003;107:3176-83. [PubMed: 12821558]

66. Sauer WH, Alonso C, Zado E, et al. Atrioventricular nodal reentrant tachycardia in patients referred for atrial fibrillation ablation: response to ablation that incorporates slow-pathway modification. Circulation 2006;114:191-5. [PubMed: 16831982]

67. Pappone C, Santinelli V, Manguso F, et al. A randomized study of prophylactic catheter ablation in asymptomatic patients with the Wolff-Parkinson-White syndrome. N Engl J Med 2003;349:180311. [PubMed: 14602878]

68. Chen YJ, Chen SA, Tai CT, et al. Role of atrial electrophysiology and autonomic nervous system in patients with supraventricular tachycardia and paroxysmal atrial fibrillation. J Am Coll Cardiol 1998;32:732-8. [PubMed: 9741520]

69. Pappone C, Santinelli V, Manguso F, et al. Pulmonary vein denervation enhances long-term benefit after circumferential ablation for paroxysmal atrial fibrillation. Circulation 2004;109:327-34. [PubMed: 14707026]

70. Aviles RJ, Martin DO, Apperson-Hansen C, et al. Inflammation as a risk factor for atrial fibrillation. Circulation 2003;108:3006-10. [PubMed: 14623805]

71. Halonen J, Halonen P, Jarvinen O, et al. Corticosteroids for the prevention of atrial fibrillation after cardiac surgery: a randomized controlled trial. Jama 2007;297:1562-7. [PubMed: 17426275]

72. Fox CS, Parise H, D'Agostino RB Sr, et al. Parental atrial fibrillation as a risk factor for atrial fibrillation in offspring. JAMA 2004;291:2851-5. [PubMed: 15199036]

73. Darbar D, Herron KJ, Ballew JD, et al. Familial atrial fibrillation is a genetically heterogeneous disorder. J Am Coll Cardiol 2003;41:2185-92. [PubMed: 12821245]

74. Ellinor PT, Yoerger DM, Ruskin JN, MacRae CA. Familial aggregation in lone atrial fibrillation. Hum Genet 2005;118:179-84. [PubMed: 16133178]

75. Chen LY, Ballew JD, Herron KJ, Rodeheffer RJ, Olson TM. A common polymorphism in SCN5A is associated with lone atrial fibrillation. Clin Pharmacol Ther 2007;81:35-41. [PubMed: 17185997]

76. Darbar D, Kannankeril PJ, Donahue BS, et al. Cardiac sodium channel (SCN5A) variants associated with atrial fibrillation. Circulation 2008;117:1927-35. [PubMed: 18378609]

77. Arnar DO, Thorvaldsson S, Manolio TA, et al. Familial aggregation of atrial fibrillation in Iceland. Eur Heart J 2006;27:708-12. [PubMed: 16428254]

78. Chen YH, Xu SJ, Bendahhou S, et al. KCNQ1 gain-of-function mutation in familial atrial fibrillation. Science 2003;299:251-4. [PubMed: 12522251]

79. Yang Y, Xia M, Jin Q, et al. Identification of a KCNE2 gain-of-function mutation in patients with familial atrial fibrillation. Am J Hum Genet 2004;75:899-905. [PubMed: 15368194]

80. Hong K, Bjerregaard P, Gussak I, Brugada R. Short QT syndrome and atrial fibrillation caused by mutation in KCNH2. J Cardiovasc Electrophysiol 2005;16:394-6. [PubMed: 15828882]

81. Xia M, Jin Q, Bendahhou S, et al. A Kir2.1 gain-of-function mutation underlies familial atrial fibrillation. Biochem Biophys Res Commun 2005;332:1012-9. [PubMed: 15922306] 
82. Olson TM, Alekseev AE, Liu XK, et al. Kv1.5 channelopathy due to KCNA5 loss-of-function mutation causes human atrial fibrillation. Hum Mol Genet 2006;15:2185-91. [PubMed: 16772329]

83. Otway R, Vandenberg JI, Guo G, et al. Stretch-sensitive KCNQ1 mutation A link between genetic and environmental factors in the pathogenesis of atrial fibrillation? J Am Coll Cardiol 2007;49:57886. [PubMed: 17276182]

84. Das S, Makino S, Melman YF, et al. Mutation in the S3 segment of KCNQ1 results in familial lone atrial fibrillation. Heart Rhythm 2009;6:1146-53. [PubMed: 19632626]

85. Ellinor PT, Nam EG, Shea MA, Milan DJ, Ruskin JN, MacRae CA. Cardiac sodium channel mutation in atrial fibrillation. Heart Rhythm 2008;5:99-105. [PubMed: 18088563]

86. Benito B, Brugada R, Perich RM, et al. A mutation in the sodium channel is responsible for the association of long QT syndrome and familial atrial fibrillation. Heart Rhythm 2008;5:1434-40. [PubMed: 18929331]

87. Makiyama T, Akao M, Shizuta S, et al. A novel SCN5A gain-of-function mutation M1875T associated with familial atrial fibrillation. J Am Coll Cardiol 2008;52:1326-34. [PubMed: 18929244]

88. Hodgson-Zingman DM, Karst ML, Zingman LV, et al. Atrial natriuretic peptide frameshift mutation in familial atrial fibrillation. N Engl J Med 2008;359:158-65. [PubMed: 18614783]

89. Brugada R, Tapscott T, Czernuszewicz GZ, et al. Identification of a genetic locus for familial atrial fibrillation. N Engl J Med 1997;336:905-11. [PubMed: 9070470]

90. Ellinor PT, Shin JT, Moore RK, Yoerger DM, MacRae CA. Locus for atrial fibrillation maps to chromosome 6q14-16. Circulation 2003;107:2880-3. [PubMed: 12782570]

91. Oberti C, Wang L, Li L, et al. Genome-wide linkage scan identifies a novel genetic locus on chromosome $5 \mathrm{p} 13$ for neonatal atrial fibrillation associated with sudden death and variable cardiomyopathy. Circulation 2004;110:3753-9. [PubMed: 15596564]

92. Volders PG, Zhu Q, Timmermans C, et al. Mapping a novel locus for familial atrial fibrillation on chromosome 10p11-q21. Heart Rhythm 2007;4:469-75. [PubMed: 17399636]

93. Hong K, Piper DR, Diaz-Valdecantos A, et al. De novo KCNQ1 mutation responsible for atrial fibrillation and short QT syndrome in utero. Cardiovasc Res 2005;68:433-40. [PubMed: 16109388]

94. Sanders P, Morton JB, Davidson NC, et al. Electrical remodeling of the atria in congestive heart failure: electrophysiological and electroanatomic mapping in humans. Circulation 2003;108:14618. [PubMed: 12952837]

95. Gollob MH, Jones DL, Krahn AD, et al. Somatic mutations in the connexin 40 gene (GJA5) in atrial fibrillation. N Engl J Med 2006;354:2677-88. [PubMed: 16790700]

96. Ellinor PT, MacRae CA. Ion channel mutations in AF: signal or noise? Heart Rhythm 2008;5:4367. [PubMed: 18313603]

97. McNair WP, Ku L, Taylor MR, et al. SCN5A mutation associated with dilated cardiomyopathy, conduction disorder, and arrhythmia. Circulation 2004;110:2163-7. [PubMed: 15466643]

98. Olson TM, Michels VV, Ballew JD, et al. Sodium channel mutations and susceptibility to heart failure and atrial fibrillation. JAMA 2005;293:447-54. [PubMed: 15671429]

99. Fatkin D, MacRae C, Sasaki T, et al. Missense mutations in the rod domain of the lamin A/C gene as causes of dilated cardiomyopathy and conduction-system disease. N Engl J Med 1999;341:171524. [PubMed: 10580070]

100. Sebillon P, Bouchier C, Bidot LD, et al. Expanding the phenotype of LMNA mutations in dilated cardiomyopathy and functional consequences of these mutations. J Med Genet 2003;40:560-7. [PubMed: 12920062]

101. Gudbjartsson DF, Arnar DO, Helgadottir A, et al. Variants conferring risk of atrial fibrillation on chromosome 4q25. Nature 2007;448:353-7. [PubMed: 17603472]

102. Larson MG, Atwood LD, Benjamin EJ, et al. Framingham Heart Study 100K project: genome-wide associations for cardiovascular disease outcomes. BMC Med Genet 2007;8 (Suppl 1):S5. [PubMed: 17903304]

103. Franco D, Campione M. The role of Pitx2 during cardiac development. Linking left-right signaling and congenital heart diseases. Trends Cardiovasc Med 2003;13:157-63. [PubMed: 12732450] 
104. Faucourt M, Houliston E, Besnardeau L, Kimelman D, Lepage T. The pitx2 homeobox protein is required early for endoderm formation and nodal signaling. Dev Biol 2001;229:287-306. [PubMed: 11203696]

105. Mommersteeg MT, Hoogaars WM, Prall OW, et al. Molecular pathway for the localized formation of the sinoatrial node. Circ Res 2007;100:354-62. [PubMed: 17234970]

106. Mitsui T, Nomura S, Okada M, et al. Hypertension and angiotensin II hypersensitivity in aminopeptidase A-deficient mice. Mol Med 2003;9:57-62. [PubMed: 12765341]

107. Benjamin EJ, Rice KM, Arking DE, et al. Variants in ZFHX3 are associated with atrial fibrillation in individuals of European ancestry. Nat Genet 2009;41:879-81. [PubMed: 19597492]

108. Gudbjartsson DF, Holm H, Gretarsdottir S, et al. A sequence variant in ZFHX3 on 16q22 associates with atrial fibrillation and ischemic stroke. Nat Genet 2009;41:876-8. [PubMed: 19597491]

109. Li D, Melnyk P, Feng J, et al. Effects of experimental heart failure on atrial cellular and ionic electrophysiology. Circulation 2000;101:2631-8. [PubMed: 10840016]

110. Yeh Y-H, Wakili R, Qi X, et al. Calcium Handling Abnormalities Underlying Atrial Arrhythmogenesis and Contractile Dysfunction in Dogs with Congestive Heart Failure. Circ Arrhythmia Electrophysiol. 2008 CIRCEP.107.754788.

111. Tisdale JE, Borzak S, Sabbah HN, Shimoyama H, Goldstein S. Hemodynamic and neurohormonal predictors and consequences of the development of atrial fibrillation in dogs with chronic heart failure. J Card Fail 2006;12:747-51. [PubMed: 17174237]

112. Rucker-Martin C, Milliez P, Tan S, et al. Chronic hemodynamic overload of the atria is an important factor for gap junction remodeling in human and rat hearts. Cardiovasc Res 2006;72:69-79. [PubMed: 16839528]

113. Vaziri SM, Larson MG, Benjamin EJ, Levy D. Echocardiographic predictors of nonrheumatic atrial fibrillation. The Framingham Heart Study Circulation 1994;89:724-30.

114. Psaty BM, Manolio TA, Kuller LH, et al. Incidence of and risk factors for atrial fibrillation in older adults. Circulation 1997;96:2455-61. [PubMed: 9337224]

115. Bode F, Katchman A, Woosley RL, Franz MR. Gadolinium decreases stretch-induced vulnerability to atrial fibrillation. Circulation 2000;101:2200-5. [PubMed: 10801762]

116. Tanaka K, Zlochiver S, Vikstrom KL, et al. Spatial distribution of fibrosis governs fibrillation wave dynamics in the posterior left atrium during heart failure. Circ Res 2007;101:839-47. [PubMed: 17704207]

117. Cha TJ, Ehrlich JR, Zhang L, et al. Dissociation between ionic remodeling and ability to sustain atrial fibrillation during recovery from experimental congestive heart failure. Circulation 2004;109:412-8. [PubMed: 14718405]

118. Zankov DP, Omatsu-Kanbe M, Isono T, et al. Angiotensin II Potentiates the Slow Component of Delayed Rectifier K+ Current via the AT1 Receptor in Guinea Pig Atrial Myocytes. Circulation 2006;113:1278-1286. [PubMed: 16534027]

119. Wang TJ, Massaro JM, Levy D, et al. A risk score for predicting stroke or death in individuals with new-onset atrial fibrillation in the community: the Framingham Heart Study. JAMA 2003;290:1049-56. [PubMed: 12941677]

120. Carlsson J, Miketic S, Windeler J, et al. Randomized trial of rate-control versus rhythm-control in persistent atrial fibrillation: the Strategies of Treatment of Atrial Fibrillation (STAF) study. J Am Coll Cardiol 2003;41:1690-6. [PubMed: 12767648]

121. Hohnloser SH, Kuck KH, Lilienthal J. Rhythm or rate control in atrial fibrillation--Pharmacological Intervention in Atrial Fibrillation (PIAF): a randomised trial. Lancet 2000;356:1789-94. [PubMed: 11117910]

122. Opolski G, Torbicki A, Kosior DA, et al. Rate control vs rhythm control in patients with nonvalvular persistent atrial fibrillation: the results of the Polish How to Treat Chronic Atrial Fibrillation (HOT CAFE) Study. Chest 2004;126:476-86. [PubMed: 15302734]

123. Van Gelder IC, Hagens VE, Bosker HA, et al. A comparison of rate control and rhythm control in patients with recurrent persistent atrial fibrillation. N Engl J Med 2002;347:1834-40. [PubMed: 12466507]

124. Wyse DG, Waldo AL, DiMarco JP, et al. A comparison of rate control and rhythm control in patients with atrial fibrillation. N Engl J Med 2002;347:1825-33. [PubMed: 12466506] 
125. Testa L, Biondi-Zoccai GG, Dello Russo A, Bellocci F, Andreotti F, Crea F. Rate-control vs. rhythmcontrol in patients with atrial fibrillation: a meta-analysis. Eur Heart J 2005;26:2000-6. [PubMed: 15872032]

126. Corley SD, Epstein AE, DiMarco JP, et al. Relationships between sinus rhythm, treatment, and survival in the Atrial Fibrillation Follow-Up Investigation of Rhythm Management (AFFIRM) Study. Circulation 2004;109:1509-13. [PubMed: 15007003]

127. Hagens VE, Ranchor AV, Van Sonderen E, et al. Effect of rate or rhythm control on quality of life in persistent atrial fibrillation. Results from the Rate Control Versus Electrical Cardioversion (RACE) Study. J Am Coll Cardiol 2004;43:241-7. [PubMed: 14736444]

128. Singh BN, Singh SN, Reda DJ, et al. Amiodarone versus sotalol for atrial fibrillation. N Engl J Med 2005;352:1861-72. [PubMed: 15872201]

129. Steinberg JS, Sadaniantz A, Kron J, et al. Analysis of cause-specific mortality in the Atrial Fibrillation Follow-up Investigation of Rhythm Management (AFFIRM) study. Circulation 2004;109:1973-80. [PubMed: 15051639]

130. Roy D, Talajic M, Nattel S, et al. Rhythm control versus rate control for atrial fibrillation and heart failure. N Engl J Med 2008;358:2667-77. [PubMed: 18565859]

131. Shelton RJ, Clark AL, Goode K, et al. A randomised, controlled study of rate versus rhythm control in patients with chronic atrial fibrillation and heart failure: (CAFE-II Study). Heart 2009;95:92430. [PubMed: 19282313]

132. Lubitz SA, Fischer A, Fuster V. Catheter ablation for atrial fibrillation. BMJ 2008;336:819-26. [PubMed: 18403546]

133. Hsu LF, Jais P, Sanders $P$, et al. Catheter ablation for atrial fibrillation in congestive heart failure. N Engl J Med 2004;351:2373-83. [PubMed: 15575053]

134. Chen MS, Marrouche NF, Khaykin Y, et al. Pulmonary vein isolation for the treatment of atrial fibrillation in patients with impaired systolic function. J Am Coll Cardiol 2004;43:1004-9.

[PubMed: 15028358]

135. Brignole M, Menozzi C, Gianfranchi L, et al. Assessment of atrioventricular junction ablation and VVIR pacemaker versus pharmacological treatment in patients with heart failure and chronic atrial fibrillation: a randomized, controlled study. Circulation 1998;98:953-60. [PubMed: 9737514]

136. McAlister FA, Ezekowitz J, Hooton N, et al. Cardiac resynchronization therapy for patients with left ventricular systolic dysfunction: a systematic review. JAMA 2007;297:2502-14. [PubMed: 17565085]

137. Gasparini M, Auricchio A, Regoli F, et al. Four-year efficacy of cardiac resynchronization therapy on exercise tolerance and disease progression: the importance of performing atrioventricular junction ablation in patients with atrial fibrillation. J Am Coll Cardiol 2006;48:734-43. [PubMed: 16904542]

138. Linde C, Leclercq C, Rex S, et al. Long-term benefits of biventricular pacing in congestive heart failure: results from the MUltisite STimulation in cardiomyopathy (MUSTIC) study. J Am Coll Cardiol 2002;40:111-8. [PubMed: 12103264]

139. Hamdan MH, Freedman RA, Gilbert EM, Dimarco JP, Ellenbogen KA, Page RL. Atrioventricular junction ablation followed by resynchronization therapy in patients with congestive heart failure and atrial fibrillation (AVERT-AF) study design. Pacing Clin Electrophysiol 2006;29:1081-8. [PubMed: 17038140]

140. Khan M, Jais P, Cummings JE, et al. Pulmonary Vein Antrum Isolation versus AV Node Ablation with Biventricular Pacing for the Treatment of Atrial Fibrillation in Patients with Congestive Heart Failure (PABA-CHF) [abstract]. American Heart Association 2006 Scientific Session. Circulation 2006; 114:2426.

141. Nasr IA, Bouzamondo A, Hulot JS, Dubourg O, Le Heuzey JY, Lechat P. Prevention of atrial fibrillation onset by beta-blocker treatment in heart failure: a meta-analysis. Eur Heart $\mathrm{J}$ 2007;28:457-62. [PubMed: 17289748] 


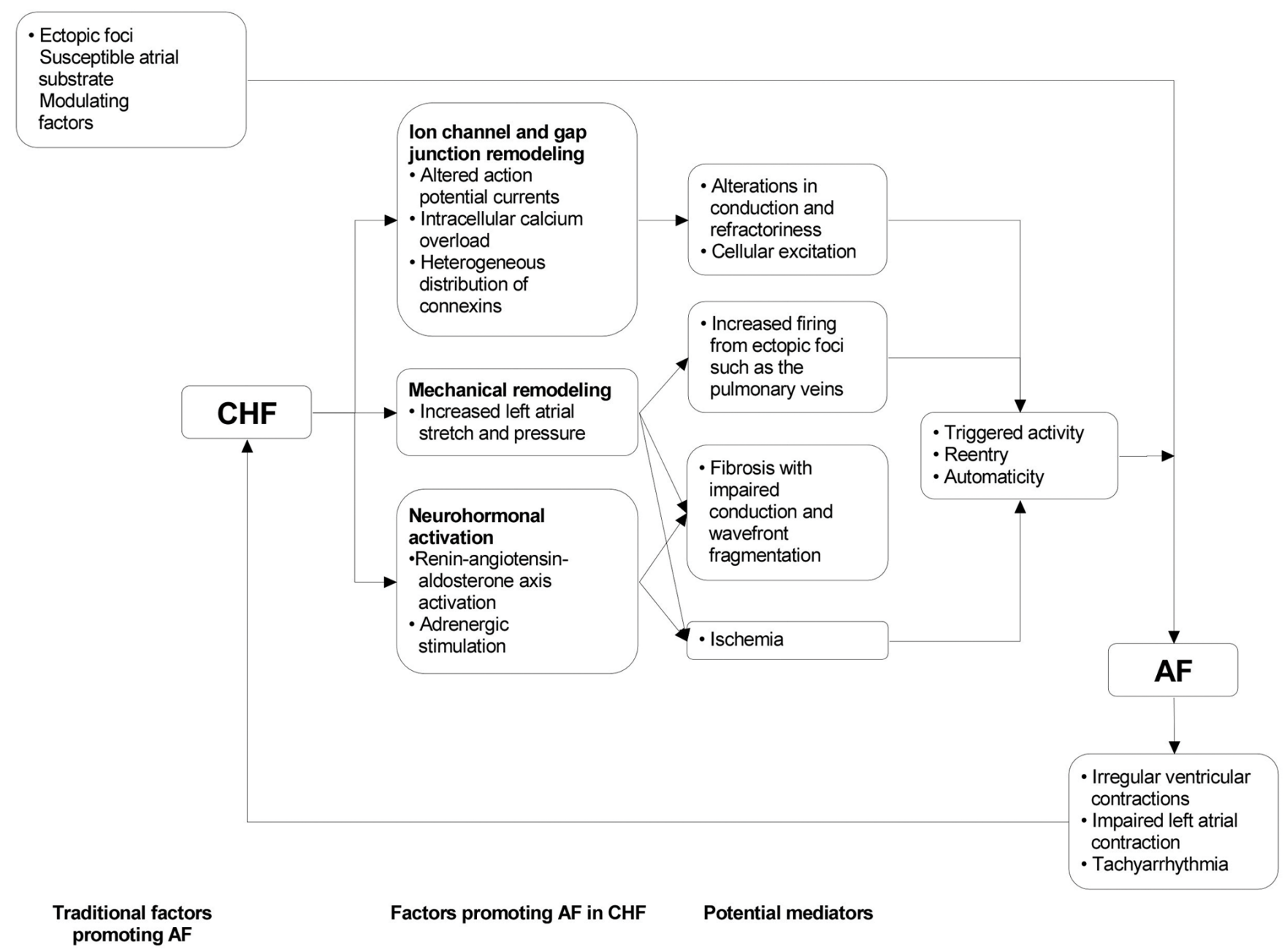

Figure 1.

Mechanisms promoting atrial fibrillation in congestive heart failure.

$\mathrm{AF}=$ atrial fibrillation, $\mathrm{CHF}=$ congestive heart failure 


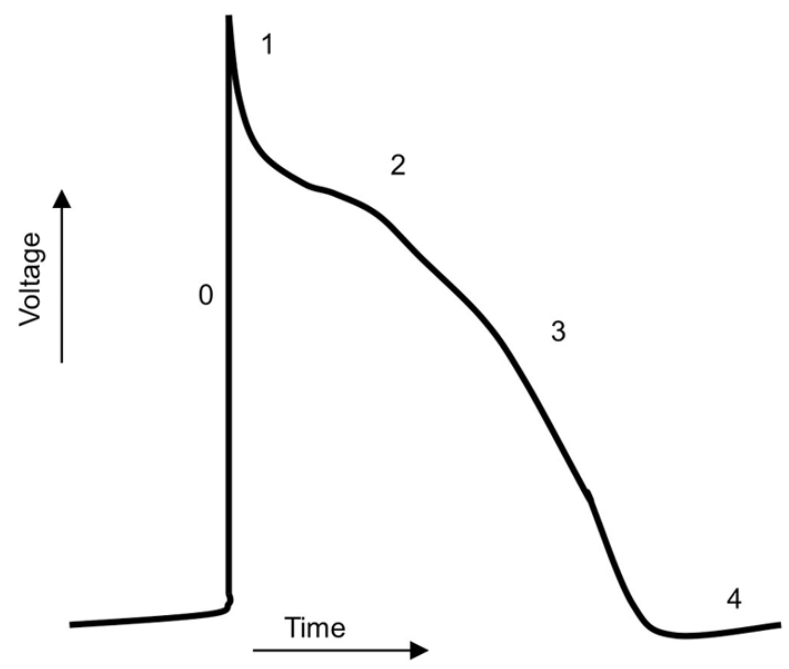

\begin{tabular}{|c|c|c|c|c|c|}
\hline $\begin{array}{l}\text { lonic } \\
\text { current }\end{array}$ & $\begin{array}{l}\text { Predominant } \\
\text { active phase }\end{array}$ & Gene & $\begin{array}{l}\text { Gain or } \\
\text { loss of } \\
\text { function }\end{array}$ & $\begin{array}{l}\text { Predicted } \\
\text { effect on } \\
\text { ARP }\end{array}$ & Reference \\
\hline$I_{\mathrm{Na}}$ & 0 & SCN5A & Loss & None & {$[85,98]$} \\
\hline$I_{\text {to }}$ & 1 & KCND3/KCNIP2 & - & - & - \\
\hline$I_{\text {Kur }}$ & 2 & KCNA5 & Loss & $\uparrow$ & [82] \\
\hline$I_{\text {CaL }}$ & 3 & CACNA1C & - & - & - \\
\hline$I_{\mathrm{Kr}}$ & 3 & KCNH2/KCNE2 & Gain & $\downarrow$ & {$[80]$} \\
\hline$I_{\mathrm{Ks}}$ & 3 & KCNQ1/KCNE1 & Gain & $\downarrow$ & {$[78,79,83,84,94]$} \\
\hline$I_{\mathrm{NCX}}$ & 3 & & - & - & - \\
\hline$I_{K 1}$ & 4 & $\mathrm{KCNJ} 2$ & Gain & $\downarrow$ & [81] \\
\hline
\end{tabular}

Figure 2.

Genetic mutations affecting ionic currents that underlie the atrial action potential. $\mathrm{ARP}=$ atrial refractory period, $\mathrm{GOF}=$ gain of function mutation, $\mathrm{LOF}=$ loss of function mutation. 


\section{Table}

Shared risk factors for atrial fibrillation and congestive heart failure.

Non-modifiable risk factors
Aging
Male gender
Genetic predisposition
Modifiable risk factors
Hypertension
Diabetes mellitus
Obesity
Hyperthyroidism
Smoking
Excessive alcohol consumption
Heart disease
Ischemic heart disease
Valve disease
Infiltrative cardiomyopathies
Myocarditis
Left ventricular systolic dysfunction
Left ventricular diastolic dysfunction
Subclinical disease
Electrocardiographic left ventricular hypertrophy
Neurohormonal activation
Inflammation

